\title{
Placental site trophoblastic tumor
}

INSERM

\section{Source}

INSERM. (1999). Orphanet: an online rare disease and orphan drug data base. Placental site trophoblastic tumor. ORPHA:99928

Placental site trophoblastic tumor is a rare gestational trophoblastic tumor (GTT; see this term) which develops from the placental implantation site and always occurs following pregnancy, voluntary termination of pregnancy (VTP) or miscarriage. 